\title{
Chemical Modification of Cobalt Ferrite Nanoparticles with Possible Application as Asphaltene Flocculant Agent
}

\author{
Oliveira, G. E. a*, Clarindo, J. E. S. , Santo, K. S. E. , Souza Jr., F. G. ${ }^{\text {b }}$ \\ a Departamento de Química - DQUI, Centro de Ciências Exatas -CCE, \\ Universidade Federal do Espírito Santo - UFES, Vitória, ES, Brasil \\ ${ }^{\mathrm{b}}$ Instituto de Macromoléculas - IMA, Universidade Federal do Rio de Janeiro - UFRJ, \\ Rio de Janeiro, RJ, Brasil
}

Received: October 31, 2012; Revised: February 15, 2013

\begin{abstract}
Asphaltenes can cause enormous losses in the oil industry, because they are soluble only in aromatic solvents. Therefore, they must be removed from the petroleum before it is refined, using flocculant agents. Aiming to find new materials that can work as flocculant agents to asphaltenes, cobalt ferrite nanoparticles were chemically modified through acid-base reactions using dodecylbenzene sulfonic acid (DBSA) to increase their lipophilicity. Nanoparticle synthesis was performed using the co-precipitation method followed by annealing of these nanoparticles, aiming to change the structural phase. Modified and unmodified nanoparticles were tested by FTIR-ATR, XRD and TGA/DTA. In addition, precipitation onset of the asphaltenes was performed using modified and unmodified nanoparticles. These tests showed that modified nanoparticles have a potential application as flocculant agents used to remove asphaltenes before oil refining, since the presence of nanoparticles promotes the asphaltene precipitation onset with the addition of a small amount of non-solvent.
\end{abstract}

Keywords: chemical modification of nanoparticles, cobalt ferrite nanoparticles, asphaltenes, flocculant agent and petroleum

\section{Introduction}

Problems associated with heavy organic fractions crystallization and deposition during the production, transport and storage of crude oils can cause enormous losses to the petroleum industry. Heavy organic fractions of crude oil include waxes, resins, asphaltenes and organometallic compounds. They can exist in different quantities, shapes and states inside the crude oil and problems associated with organic deposits can be found at any stage of the process of oil production, from the reservoir through to the refinery ${ }^{1-3}$. The deposits are formed by several organic compounds; among them, asphaltenes are the most difficult to remediate, because they are the most polar fraction and are insoluble in aliphatic solvents, for instance n-heptane, and soluble in aromatic solvents, for instance toluene. Asphaltenes present a polyaromatic core circled by cyclic rings with aliphatic chains in the periphery. They can cause enormous losses in the oil industry, because they are soluble only in aromatic solvents, such as benzene and toluene; therefore, asphaltenes must be removed from the petroleum before it is refined. To remove asphaltenes from the petroleum, a flocculant agent is used.

Asphaltene precipitation has been investigated by several research groups and, among the possible solutions, nanotechnology methods are very promising. In fact, nanomaterials development has grown up in

*e-mail: geiza.oliveira@ufes.br several application fields, such as chemistry, physics and engineering. Materials in nanoscale have shown much better properties in comparison to the same materials in macroscopic scale.

Nanomaterials in general can be roughly classified into two categories. If the characteristic length of the microstructure, such as the grain size of a polycrystal, is in the nanometer range, it is called a nanostructured material. If at least one of the overall dimensions of a structural element is in the nanometer range, it may be called a nanosized structural element. This may include nanoparticles, nanobelts, nanowires, nanofilms, etc. The reduced coordination of atoms near a free surface induces a corresponding redistribution of electronic charge, which alters the binding situation. As a result, the energy of these atoms will, in general, be different from that of the atoms in the bulk. In macroscopic scale materials, the surface region is typically very thin, only a few atomic layers ${ }^{4}$. However, in nanoscale there are only surface atoms, explaining the observed difference in the properties between the nanoscopic and macroscopic scale of the same material. Another inherent feature of nanomaterials is a very high surface area, which promotes better interaction between the particles and the medium ${ }^{5}$.

Among several possible morphologies, equiaxial nanoparticles present a lot of applications in chemistry, physics, engineering, and medicine, among other fields ${ }^{6-9}$. 
In the crude oil industry, equiaxial nanoparticles are used mainly as catalysts in refining catalytic processes ${ }^{10}$. In a new application, cobalt ferrite nanoparticles were chemically modified and used as asphaltene flocculant agent. These nanoparticles were chemically modified through acid-base reactions, using dodecylbenzene sulfonic acid (DBSA). These modifications are able to increase the lipophilicity of the nanoparticles, allowing a better interaction between nanoparticles and the asphaltenes. This better interaction is able to promote the association among the asphaltenes molecules. In addition, these nanoparticles present superparamagnetic properties ${ }^{11-13}$, which provide a technological advantage to the magnetic removal of the asphaltenes deposits before the refining process.

\section{Experimental}

\subsection{Material}

Hydrochloric acid (HCL), ferric chloride $\left(\mathrm{FeCl}_{3}\right)$, cobalt chloride II $\left(\mathrm{CoCl}_{2}\right)$, sodium hydroxide $(\mathrm{NaOH})$, sodium chloride $(\mathrm{NaCl}), \mathrm{n}$-heptane and toluene (analytical grade) were purchased from Vetec (Rio de Janeiro, Brazil). DBSA, in commercial grade, was purchased from Solquim LTDA (Rio de Janeiro, Brazil), and crude oil was kindly donated by LabPetro - Laboratório de Petróleo/DQUI/UFES.

\subsection{Nanoparticles synthesis}

Cobalt ferrite nanoparticles were prepared through the homogeneous precipitation technique using a $\mathrm{FeCl}_{3}$ solution (2.0 mol. $\left.\mathrm{L}^{-1}\right)$, a $\mathrm{CoCl}_{2}$ solution $\left(1.0 \mathrm{~mol} . \mathrm{L}^{-1}\right)$ and deionized water, under continuous agitation. The reaction product was precipitated by the slow addition of $\mathrm{NaOH}$ solution, until the $\mathrm{pH}$ equaled 13, under continuous agitation. After this, the particles were obtained by filtering; they were washed several times with water and finally dried at $60^{\circ} \mathrm{C}$ in an oven. The particles obtained were converted into spinell structures through annealing at $200{ }^{\circ} \mathrm{C}$ for one hour.

\subsection{Chemical modification of the nanoparticles}

Chemical modification was carried out by surface acid-base reaction, using DBSA. A 20\% DBSA solution was prepared using an isovolumetric water/ethanol mixture. Soon afterwards, one gram of the nanoparticles was dispersed in this solution and continuously stirred for one hour. After this, the nanoparticles were filtered, washed and dried at $60{ }^{\circ} \mathrm{C}$ in an oven.

\subsection{Characterization of the materials}

Modified and unmodified nanoparticles were characterized by infrared spectroscopy with Fourier transformation using an attenuated total reflectance accessory (FTIR-ATR), X-ray diffraction (XRD) and thermogravimetric analysis (TGA/DTA). The FTIR analyses were performed in a Pike spectrophotometer, FTLA 200, using a resolution of $4 \mathrm{~cm}^{-1}$ and 30 scans. The XRD analyses were carried out using a Shimatzu diffractometer, XRD 6000 , using an electric potential difference (ddp) equal to $40 \mathrm{kV}$ and an electric current equal to $30 \mathrm{~mA}$. Scanning was performed in the $2 \theta$ range between 10 and $90^{\circ}$, with steps of $0.05^{\circ} / \mathrm{min}$. The used radiation was $\mathrm{K} \alpha_{\mathrm{Cu}}(\lambda=1.5418 \AA)$. The TGA/DTA analyses were performed using a TA Instruments SDT Q600 thermoanalyzer, under nitrogen flux, with a heating rate equal to $5{ }^{\circ} \mathrm{C} / \mathrm{min}$, a temperature range from 25 to $700{ }^{\circ} \mathrm{C}$ and an empty alumina pan as a reference.

The asphaltenes were extracted by solubility differences using n-heptane and toluene as solvents in a soxleth extractor. They were characterized by FTIR and XRD, using the similar conditions applied to nanoparticles. The TGA analysis was performed using a TA Instruments SDT Q600 thermoanalyzer, under nitrogen flux, with a heating rate equal to $10^{\circ} \mathrm{C} / \mathrm{min}$, a temperature range from 25 to $400{ }^{\circ} \mathrm{C}$ and an empty aluminum pan as a reference.

\subsection{Asphaltene precipitation onset tests}

The asphaltene precipitation onset test was performed using three solutions: the first was a pure asphaltenes solution, the second was a solution of asphaltenes containing unmodified nanoparticles and the third was a solution of asphaltenes containing modified nanoparticles. The asphaltenes concentration was equal to $1 \% \mathrm{wt}$ and the nanoparticles concentration was equal to $1000 \mathrm{ppm}$. The analyses were carried out in the UV-Vis spectrophotometer Varian, Cary, using a wavelength of $850 \mathrm{~nm}$; n-heptane was used as a flocculant agent.

\section{Results and Discussion}

Figure 1 shows the FTIR spectra for the unmodified and modified cobalt ferrite. The unmodified nanoparticles FTIR spectrum showed a wide characteristic band around $3350 \mathrm{~cm}^{-1}$ related to stretching of the $\mathrm{O}-\mathrm{H}$ bond present in the $\mathrm{FeOH}$. Another characteristic band, associated with the presence of structural water, is visible at $1630 \mathrm{~cm}^{-1}$. The bands that appeared at 650 and $590 \mathrm{~cm}^{-1}$ are characteristic of stretching of the $\mathrm{Fe}-\mathrm{O}$ bond. In the modified nanoparticles spectrum, besides the characteristic bands of the unmodified

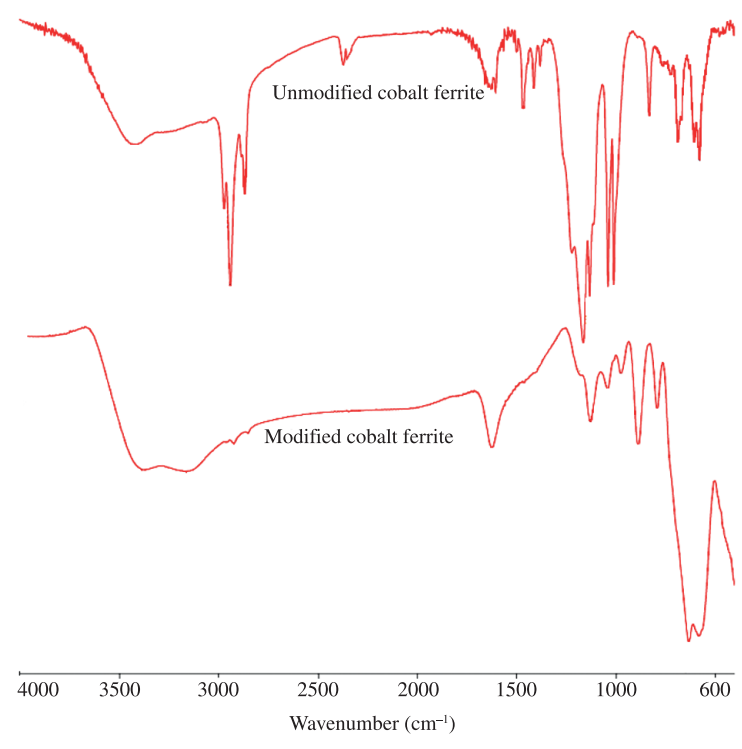

Figure 1. FTIR spectra to the unmodified and modfied cobalt ferrite. 
nanoparticles, characteristic bands of the DBSA can also be observed, such as axial deformation of the C-H bond at 2950, 2930 and $2850 \mathrm{~cm}^{-1}$ and symmetric and asymmetric axial deformations of $\mathrm{SO}_{2}$ at 1160 and $1150 \mathrm{~cm}^{-1}$, respectively. Moreover, the sulfoxide group presence is assigned by a characteristic band around $1036 \mathrm{~cm}^{-1}$. Angular deformation in-plane-ring is seen at $1002 \mathrm{~cm}^{-1}$. The bands from 825 to 580 are characteristic of out-plane-ring angular vibrations of the aromatic hydrogens.

Figure 2 presents the diffractogram of the modified nanoparticles and unmodified nanoparticles. The diffractogram of the unmodified nanoparticles shows diffraction peaks at values of $2 \theta$ equal to $30.3^{\circ}, 35.6^{\circ}, 53.3^{\circ}$ and $62.9^{\circ}$, which correspond to crystal planes (220), (311), (422) and (440), respectively, in the spinel structure of an orthorhombic cell. Moreover, these nanoparticles have a crystallinity of $(81 \pm 1) \%$, calculated using the Ruland method $^{14}$ and size crystallite $(\mathrm{Lc})$ of $(16.9 \pm 1.5) \mathrm{nm}$, determined by Scherer equation at (311). The diffractogram of the modified nanoparticles does not shows any changes in the nanoparticles structure, keeping the spinel structure of an orthorhombic cell, since there are no changes in diffraction peaks. These modified nanoparticles have a crystallinity of $(83 \pm 2) \%$, which was also calculated according Ruland method, ${ }^{14}$ and size crystallite $(\mathrm{Lc})$ of $(16.7 \pm 1.5) \mathrm{nm}$, also determined by the Scherer equation at (311). Obtained Lc values are statistically equal, indicating no changes in the structure of the cobalt ferrite core.

The TGA analysis of the unmodified cobalt ferrite shows two events of weight losses. The first is related to the output of adsorbed water of the nanoparticles surface, at around $130{ }^{\circ} \mathrm{C}$. The second is associated with the outlet of hydration water, these water molecules are chemically linked to particle structure, and this occurs between 130 and $150{ }^{\circ} \mathrm{C}$. Total weight loss in the unmodified cobalt ferrite is around $18 \%$. The TGA analysis of the modified cobalt ferrite presents five events of weight loss. The first occurs from ambient temperature to $66^{\circ} \mathrm{C}$, and is related to partial loss of water and light organic compounds from DBSA decomposition. The second is associated with the outlet of the residual adsorbed water; other light organic compounds and the hydration water exit at the start. The third weight loss event is connected to the elimination of residual hydration water and organic matter, and is observed between 200 and $300{ }^{\circ} \mathrm{C}$. The event from 300 to $520^{\circ} \mathrm{C}$ is related to hydration water in the nanoparticles core, which needs more time and a higher temperature for the diffusion to occur. The last weight loss event is associated mainly with the disruption of the spinell structure, which results in hematite and free cobalt. The total weight loss was $22 \%$; this means that around $4 \%$ corresponds to organic matter from chemical modification.

The asphaltenes FTIR spectrum shows typical characteristic bands. The wide characteristic band that appears around $3500 \mathrm{~cm}^{-1}$ is referent to the stretching of $\mathrm{OH}$ group; this band is wide because the $\mathrm{OH}$ group is able to form a hydrogen bond. The doublet observed at 2920 and $2845 \mathrm{~cm}^{-1}$ corresponds to $\mathrm{CH}_{2}$ and $\mathrm{CH}_{3}$ stretching. The characteristic band at $1597 \mathrm{~cm}^{-1}$ is related to $\mathrm{C}=\mathrm{C}$ and $\mathrm{C}=\mathrm{O}$ coupled bonds. The $\mathrm{CH}_{3}$ asymmetric and symmetric absorption appears at 1453 and $1374 \mathrm{~cm}^{-1}$, respectively.
The sulfoxide group $\left(\mathrm{C}_{2} \mathrm{~S}=\mathrm{O}\right)$ characteristic band is seen at $1035 \mathrm{~cm}^{-1}$. The characteristic band at 867 and $805 \mathrm{~cm}^{-1}$ is associated with $\mathrm{C}-\mathrm{H}$ out-of-plane vibration of the ring, while the characteristic band at $725 \mathrm{~cm}^{-1}$ is related to $\mathrm{C}-\mathrm{H}$ in-of-plane vibration of the ring.

The asphaltene diffractogram presents feature a predominantly amorphous material, with an amorphous halo in the diffractogram. Using the Ruland method ${ }^{14}$, it is possible determine the crystallinity of the asphaltenes. The crystallinity is equal to $(23 \pm 2) \%$, which confirms the amorphous feature of the asphaltenes. It is expected that once asphaltenes suffer self-aggregation, this prevents the perfect package. The asphaltenes TGA analysis shows two events of weight loss. The first occurs between 150 and $365^{\circ} \mathrm{C}$ and is associated with maltenes degradation. The maltenes are formed by saturated, aromatic and resin compounds, all of which are soluble in n-heptane. The second is related to the asphaltenic fraction degradation itself. The asphaltenes presented a weight loss of around $60 \%$ until $530{ }^{\circ} \mathrm{C}$.

Figure 3 presents the graphic of asphaltenes precipitation onset. Initially, there is a decrease in the absorbance values with an increase of the n-heptane amount; this is due to a dilution effect. Following this, there is an increase in the absorbance value with the addition of more n-heptane;

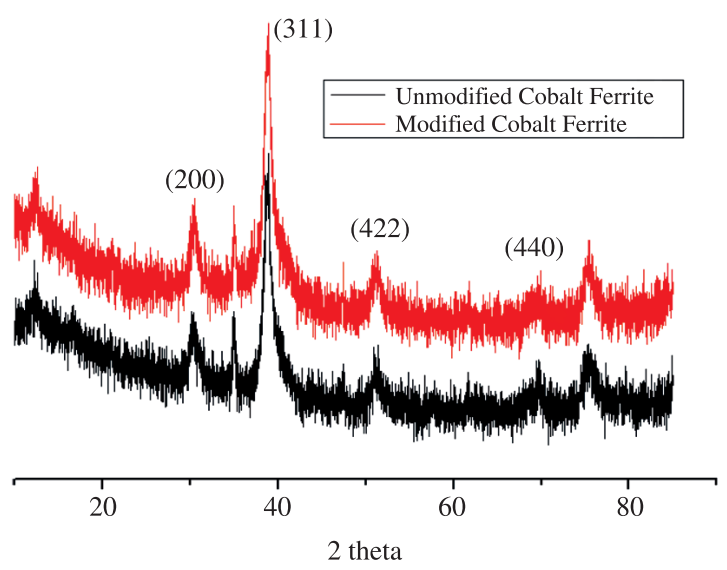

Figure 2. Diffractogram of the unmodified and modified cobalt ferrite nanoparticles.

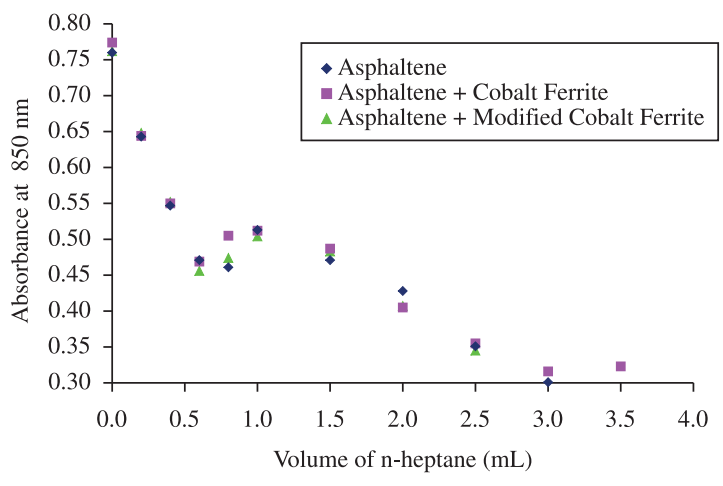

Figure 3. Asphaltenes precipitation onset without and with unmodified and modified nanoparticles. 
this is because there is the appearance of the first particles of asphaltenes that scatter light. The absorbance increases until all asphaltene is precipitated; after this, the absorbance decreases again due to a dilution effect. The inflection point of the curve corresponds to the onset of asphaltenes precipitation. It can be observed that the onset of asphaltenes precipitation occurs with the addition of $0.8 \mathrm{~mL}$ of $\mathrm{n}$-heptane. In the presence of the unmodified nanoparticles, this value falls to $0.6 \mathrm{~mL}$, suggesting that the unmodified nanoparticles promote asphaltene aggregation. On the other hand, the presence of modified nanoparticles in the system does not produce any change in the asphaltenes precipitation onset, remaining at $0.6 \mathrm{~mL}$ of n-heptane. This means that the particles are able to promote the asphaltene aggregation. Previous results ${ }^{15}$ have shown that changes in the chemical reactions can be performed to obtain distinct results. These changes can be used to adjust the modified nanoparticles to each kind of asphaltenes and application.

\section{References}

1. Boukadi A, Philp RP and Thanh NX. Characterization of Paraffinic Deposits in Crude Oil Storage Tanks Using High Temperature Gas Chromatography. Applied Geochemistry. 2005; 20:1974-1983. http://dx.doi.org/10.1016/j. apgeochem.2005.06.004

2. Monteagudo JEP, Silva LFLR and Lage PLC. Scaling Laws for Network Model Permeability: Application to Wellbore Oil Flow Simulation with Solid Deposition. Chemical Engineering Science. 2003; 32:179-190.

3. Maity SK, Anchieyta J, Soberanis L and Alonso F. Catalysts for Hydroprocessing of Maya Heavy Crude. Applied Catalysis A: General. 2003; 253:125-134. http://dx.doi.org/10.1016/ S0926-860X(03)00499-X

4. Dingreville R, Qu J and Cherkaoui M. Surface free energy and its effect on the elastic behavior of nano-sized particles, wires and films. Journal of the Mechanics and Physics of Solids. 2005; 53:1827-1854. http://dx.doi.org/10.1016/j. jmps.2005.02.012

5. Lopes MC, Souza Junior FG and Oliveira GE. Espumados magnetizáveis úteis em processos de recuperação ambiental. Polímeros. 2010; 20(5):359-365. http://dx.doi.org/10.1590/ S0104-14282010005000054

6. Fernández L, Arranz G, Palacio L, Soria C, Sánchez M, Pérez $G$ et al. Functionalization of alumina cores by polyvinylpirrolidone: properties of the resulting biocompatible nanoparticles in aqueous suspension. Journal of Nanoparticles Research. 2009; 11:341-354. http://dx.doi.org/10.1007/s11051008-9409-9

7. Ray SS and Okamoto M. Polymer/layered Silicate nanocomposites: a Review from Preparation to Processing. Progress in Polymer Science. 2003; 28:1539-1641. http:// dx.doi.org/10.1016/j.progpolymsci.2003.08.002

8. Sundaresan A and Rao CNR. Ferromagnetism as a Universal Feature of Inorganic Particles. Nanotoday. 2009; 4:96-106. http://dx.doi.org/10.1016/j.nantod.2008.10.002

\section{Conclusion}

Cobalt ferrite nanoparticles can be modified to increase their lipophilicity through the insertion of hydrocarbon chains in their surfaces, using acid-base reactions with organic acids, such as that with dodecylbenzene sulfonic acid. The results show that the chemical modification does not change the nanometric size of the particles, it simply increases their lipophilicity. These particles, without chemical modification, present potential use as flocculant agents for asphaltene, since they are able to decrease asphaltene precipitation onset.

\section{Acknowledgments}

The authors thank to the FAPES (Processes $53056981 / 2011$ and 54673038/2011) and the CAPES/Nanobiotec for the financial support. The authors also thank and the UFES/CNPq for the scholarship students, the LabPetro for the FTIR and TGA analyses and de LMC for the XRD analyses.

9. Qin GW, Darain F, Wang H and Dimitrov K. Surface modification of permalloy $\left(\mathrm{Ni}_{80} \mathrm{Fe}_{20}\right)$ nanoparticles for biomedical applications. Journal of Nanoparticles Research. 2011; 13:45-51. http:// dx.doi.org/10.1007/s11051-010-0101-5

10. Li W, Zhu J and Qi J. Application of Nano-Nickel Catalyst in the Viscosity Reduction of Liaohe Extra-Heavy Oil by Aqua-Thermolysis. Journal of Fuel Chemistry and Thecnology. 2007; 35:176-180. http://dx.doi.org/10.1016/ S1872-5813(07)60016-4

11. Herea DD, Chiriac HandLupu N. Preparation and characterization of magnetic nanoparticles with controlled magnetization. Journal of Nanoparticles Research. 2011; 13(9):4357-4369. http://dx.doi.org/10.1007/s11051-011-0385-0

12. Bhattacharya D, Sahu SK, Banerjee I, Das M, Mishra D, Maiti TK et al. Synthesis, characterization, and in vitro biological evaluation of highly stable diversely functionalized superparamagnetic iron oxide nanoparticles. Journal of Nanoparticles Research. 2011; 13 (1); 4173-4188. http://dx.doi. org/10.1007/s11051-011-0362-7

13. Karimi A, Denizot B, Hindré F, Filmon R, Greneche JM, Laurent $\mathrm{S}$ et al. Effect of chain length and electrical charge on properties of ammonium-bearing bisphosphonate-coated superparamagnetic iron oxide nanoparticles: formulation and physicochemical studies. Journal of Nanoparticles Research. 2010; 12:1239-1248. http://dx.doi.org/10.1007/ s11051-009-9815-7

14. Ruland W. X-ray determination of crystallinity and diffuse disorder scattering. Acta Crystallographica. 1961; 14:11801185. http://dx.doi.org/10.1107/S0365110X61003429

15. Oliveira GE, Santo KSE, Clarindo JES and Souza Junior FG. Structured Nanoparticles Chemically Modified Applied to Control of Organic Deposition in the Crude Oil Industry. In: Proceedings of the World Congress on Engineering and Technology - CET; 2011; Shanghai, China. Shanghai; 2011. 